\title{
3-Dimensional Volumetric Analysis of Double Socket-shield for Maximum Tissue Preservation at Immediate Implant Replacement of Multi-Rooted Teeth, A Case Report
}

\author{
Maher Abdullatif Walid* \\ Department of Oral Medicine and Periodontology, College of Dentistry, Qassim University, Qassim, Saudia Arabia \\ *Corresponding author: maherwalid14@hotmail.com
}

\begin{abstract}
Extraction Socket Healing undergoes a remodeling process that leads to vertical and horizontal tissue loss. Ridge volume alteration embeds a huge challenge on restoratively oriented three-dimensional placement of dental Implants. Socket shield technique demonstrated a histologic and clinical evidence on preventing soft and hard tissue alteration following tooth extraction. This case report describes an immediate implant placement with modification on socket-shied technique, where a buccal and palatal tooth fragments where prepared on buccal and palatal roots respectively of a failing upper first premolar, with two divergent roots. 3D deviation analysis of alveolar bone showed minimal loss of volume (-0.052mm, Avg+/-: 0.128/-0.232, SD 0.48), as well as, 3D deviation analysis of the ridge showed minimal loss of volume $(-0.122 \mathrm{~mm}$, Avg+/-: 0.029/-0.202, SD 0.263). This Double Socketshield procedure showed to be a feasible treatment option for maximum tissue preservation at immediate implant replacement of multi-rooted teeth.
\end{abstract}

Keywords: socket-shield, multi-rooted teeth, ridge preservation, volumetric measurement, immediate implant placement, tooth retention

Cite This Article: Maher Abdullatif Walid, “3-Dimensional Volumetric Analysis of Double Socket-shield for Maximum Tissue Preservation at Immediate Implant Replacement of Multi-Rooted Teeth, A Case Report.” International Journal of Dental Sciences and Research, vol. 6, no. 3 (2018): 57-65. doi: 10.12691/ijdsr-6-3-2.

\section{Introduction}

Immediate implant placement is a complex surgical procedure, mainly because of the cascade of events following tooth extraction [1,2]. Based on clinical evidence, complete maintenance of ridge volume following tooth extraction with socket augmentation procedure utilizing currently available materials cannot be entirely eliminated, due to the fact that resorption is a multifactorial phenomenon that is partially related to loss of blood supply to alveolar bone that is derived from the periodontal ligament (PDL) prior to tooth extraction $[3,4,5]$.

In 1950s, a concept of retention of tooth by submergence of roots was introduces originally to preserve alveolar ridge dimension and limit tissue alteration under removable prosthesis [6,7]. Later, Malmgren reported successful tissue regeneration around submerged roots [8]. Salama and coworkers, 2007, reported entire preservation of the alveolar ridge and attachment apparatus when developing pontic sites beneath fixed partial dentures [9]. In their technique, they decoronated the tooth to $1 \mathrm{~mm}$ above the crestal bone in order to preserve the supra-crestal dento-gingival fibers, as a result, it had been showed that retention of the root with its periodontal ligament, interconnected with the bundle bone avoids the physiologic remodeling of the extraction socket, as well as, retention of supra- crestal fibers helps in preservation of interdental papilla [9,10].

The socket shield (SS) technique was recently introduced in clinical implant dentistry that provides a promising adjunctive treatment for management of challenging immediate implant placement cases [11]. The procedure is to retain the buccal fragment of the tooth root approximately $1 \mathrm{~mm}$ coronal to the buccal bone crest with intact physiologic relation to its buccal. The principle is to section the tooth root with its attachment apparatus that is intended to remain vital and undamaged in the socket in order to support the thin buccal plate from being collapsed [11].

The first objective of the following case report is to presents a modified treatment option for multi rooted teeth, where a buccal and palatal socket shields can be prepared for maximum preservation of ridge volume. The second objective is to compare three-dimensional (3D) pre- and 6 months post- surgical scanned casts and Cone-BeamComputed-Tomographic (CBCT) data-sets to assess 3D volumetric changes in ridge and underlying alveolar bone by using this modified technique.

\section{Case Report}

A 26-year-old male patient who is healthy and non-smoker presented for definitive treatment of a maxillary right first 
premolar. The tooth was carious and the crown was destroyed almost $1 \mathrm{~mm}$ above gingival margin (Figure 1: a,b). The patient had high functional demands and moderate aesthetic expectation.

In the first visit a rubber base (1 step, Express TM VPS impression Material, Putty and Light Body, 3M, USA) impression of the upper arch, this impression was poured in a hard stone using a vacuum machine to generate a pre-surgical study cast. A CBCT (Dentsply Sirona GALLILIOS 3D, Germany) was taken to study this case. Analysis of CBCT (BlueSkyPlan3.29.28, BlueSkyBio, USA) showed that the tooth has two divergent roots with the tip of the buccal root tilted palatally, thin buccal plate with fenestration in the apical level of the buccal root, and thin palatal plate. The bucco-palatal width at the crestal bone level and every $2 \mathrm{~mm}$ apically are demonstrated in (Table 1) (Figure 1: c,d,e,f). Treatment options included: 1) extraction and replacement with 3-unit bridge, 2) implant therapy with crown restoration.

In discussion with the patient, Implant treatment was selected for this case. In planning for the surgery, and in order to overcome the expected post extraction ridge remodeling, a modified socket shield technique with immediate placement and provisionalization of a root-form implant was selected. Modified socket shield procedure included the preparation of a buccal shield on the buccal root, and palatal shield on the palatal root in an attempt to have maximum preservation of tissue. According to this, CBCT planning showed enough space and bone for a $3.5 \mathrm{X} 13 \mathrm{~mm}$ implant (Figure 2: a,b,c,d).

The patient was covered with 1g Augmentin BID, and Diclofenac Potassium 50mg BID, that started one day before the surgery and lasted for 4 days after the surgery.

Following local anesthesia of the treatment site the buccal root was sectioned in a mesio-distal direction along its long axis as far apical as was possible using a long shank root resection bur (Komet Dental, Germany) coupled to a hydrated high-speed handpiece. This was accompanied with elevation of esthetic buccal flap and apicectomy in order to remove the curved apex of buccal root (Figure 3: a,b).

The same procedure was performed with the palatal root that was sectioned in a mesio-distal direction along its long axis as far apically as possible. The two roots where separated in the furcation area, and a Periotome \#1 (Nordent, USA) was inserted in the furcation area to severe the periodontal ligament along the palatal section of the buccal root and buccal section of the palatal root, with high intention of preserving the buccal and palatal fragments of the two roots respectively unmanipulated and attached to the tooth socket.

Table 1. Bucco-palatal measurement of the bone at examination and after crown delivery

\begin{tabular}{|c|c|c|c|}
\hline & At examination & After crown delivery & change \\
\hline At bone crest & 10.44 & 10.36 & -0.08 \\
\hline $\mathbf{2 m m}$ & 10.40 & 10.29 & -0.11 \\
\hline $\mathbf{4 m m}$ & 10.55 & 10.72 & +0.17 \\
\hline $\mathbf{6 m m}$ & 10.84 & 10.92 & +0.08 \\
\hline $\mathbf{8 m m}$ & 10.76 & 9.53 & -1.23 \\
\hline $\mathbf{1 0 m m}$ & 10.11 & 9.15 & -0.96 \\
\hline
\end{tabular}

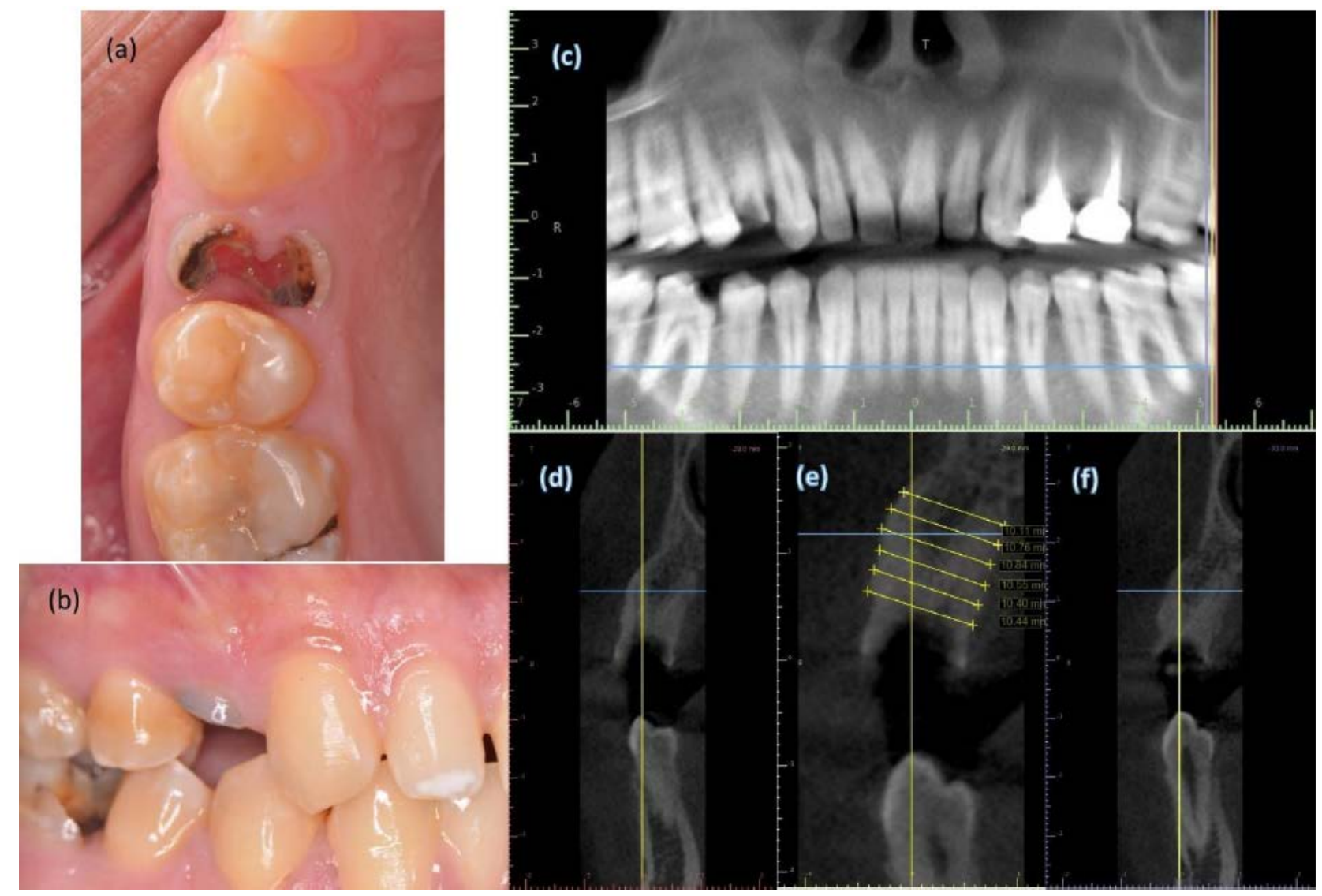

Figure 1. Pre-surgical views of maxillary right first premolar: a: occlusal view. b: buccal view. c: pre-operative panoramic view. d, e, f: pre-operative cross section view 


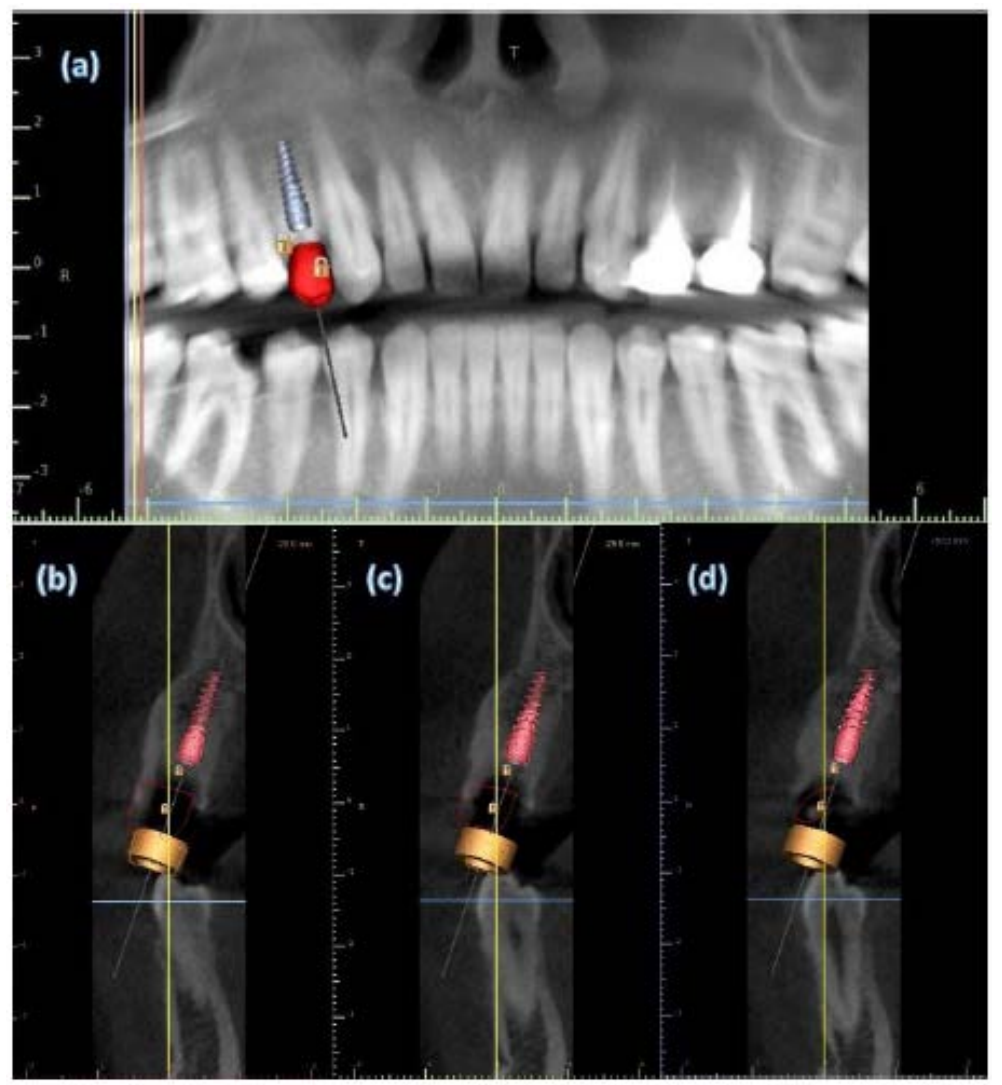

Figure 2. Blue-Sky treatment plan with 3.5X13mm root-form implant: a: Panoramic view. b, c, d: Cross section view

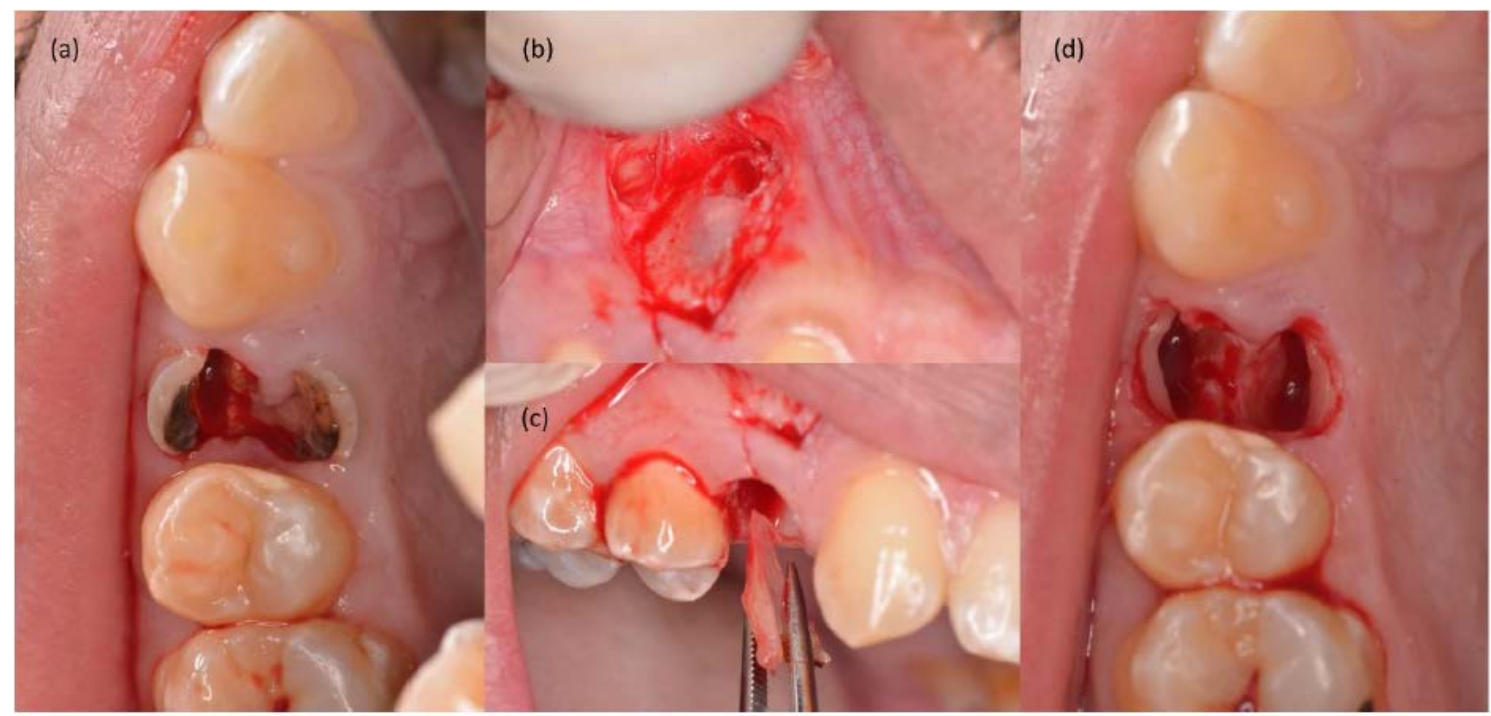

Figure 3. Surgical Procedure: a: socket shield preparation of the buccal root. b: Elevation of esthetic flap for buccal root apicectomy, apicectomy of the buccal root. c: removal of the central fragments of the buccal and palatal roots. d: Preparation of the Buccal and palatal shields

The central parts of the roots were then carefully removed (Figure 3: c), and the remaining sections of the roots were then reduced coronally to $1 \mathrm{~mm}$ above the alveolar crest and thinned slightly to a concave contour by careful preparation in an apico-coronal and mesio-distal direction with a long shank round diamond bur (Komet Dental, Germany). The tooth socket was curetted and irrigated with normal saline to remove any infected remnants and the buccal and palatal shields were checked for stability using a sharp prob. (Figure 3: d).

An osteotomy was then sequentially prepared in the interradicular bone to place a $3.5 \times 13 \mathrm{~mm}$ implant (NobelActive Internal NP, Nobel Biocare, Sweden), where the implant platform would be $4 \mathrm{~mm}$ apical to the free gingival level (Figure 4: a,b,c). The jumping gap around the implant was then filled with Bioactive Synthetic Bone Graft (NOVA BONE PUTTY, USA) (Figure 4: d).

The primary stability of the implant was gained from the radicular and apical bone, and a customized provisional healing abutment was constructed chairside with an SShaped emerging profile to support the coronal tissue, as well as, ensuring adequate space between the customized healing abutment and the buccal and palatal shields (Figure 5: a). The buccal esthetic flap was closed with absorbable suture (SURGICRYL PGA 5/0) (Figure 5: b). 
After 6 months of uneventful healing, the patient returned to continue with the restoration phase. Another rubber base (1 step, Express TM VPS impression Material, Putty and Light Body, 3M, USA) impression of the upper arch, this impression was poured in a hard stone using a vacuum machine to generate a post-surgical study cast. An open-tray impression was taken, and a porcelain fused to metal (PFM) crown was fabricated. This crow was cemented to the abutment (Snappy Abutment 5.5, Conical Connection, 1.5, Nobel Biocare, Sweden) extra orally with resin cement (RelyX Unicem Self-Adhesive, 3M, USA) and turned into screw retained crown in order to avoid cement extrusion in implant sulcus area. The crown was then torqued in place to 35n/cm (Figure 6: a).

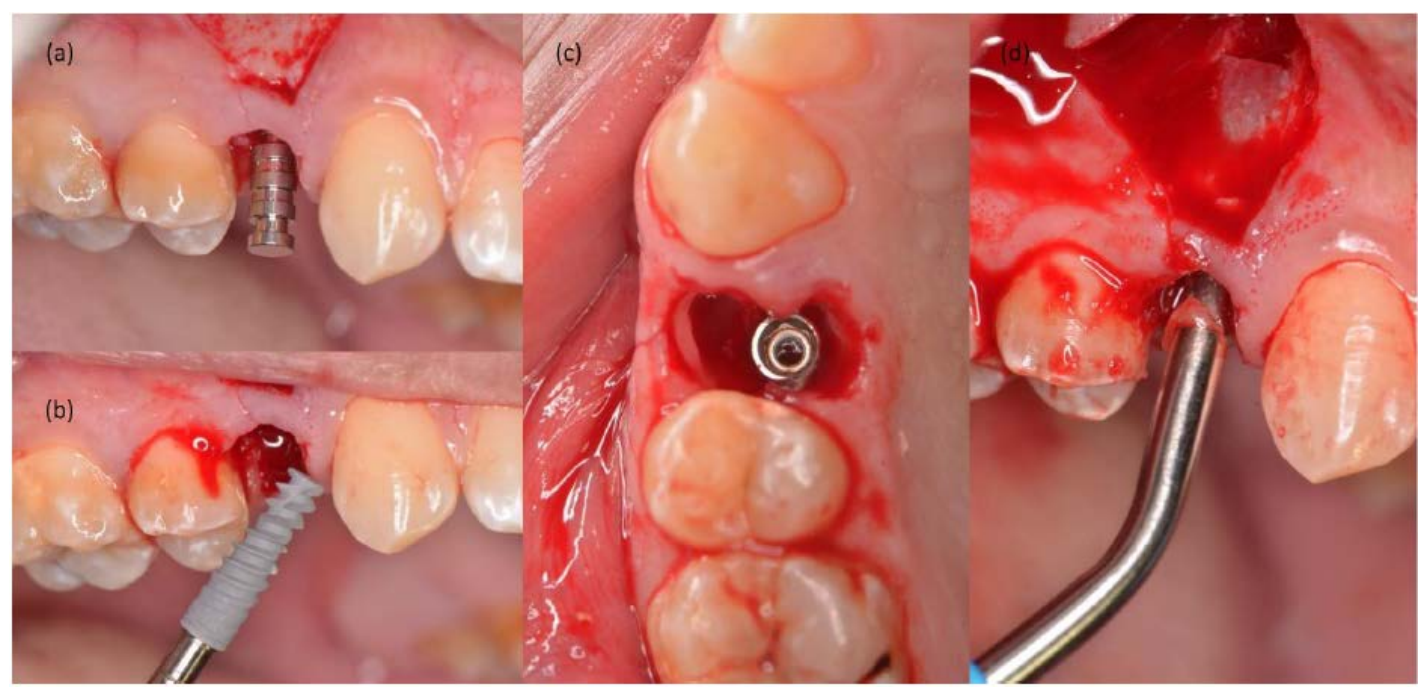

Figure 4. implant placement and grafting: a: osteotomy site preparation (Direction pin). b: 3.5X13 NobelActive Internal NP implant. c: implant in place. d: BioActive Synthetic Bone Graft (Nova Bone Putty) to fill the distance gap around the implant

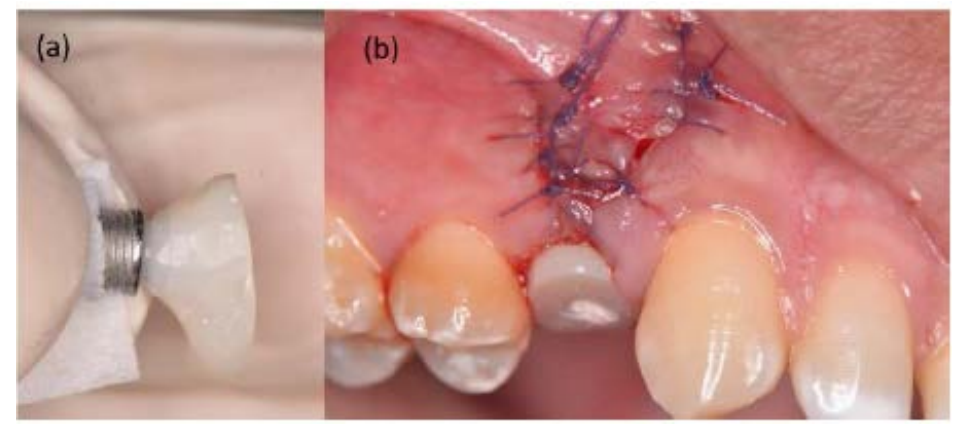

Figure 5. Surgical site closure: a: customized healing abutment with S-shaped emergence profile. b: customized healing abutment in place, esthetic flap closure

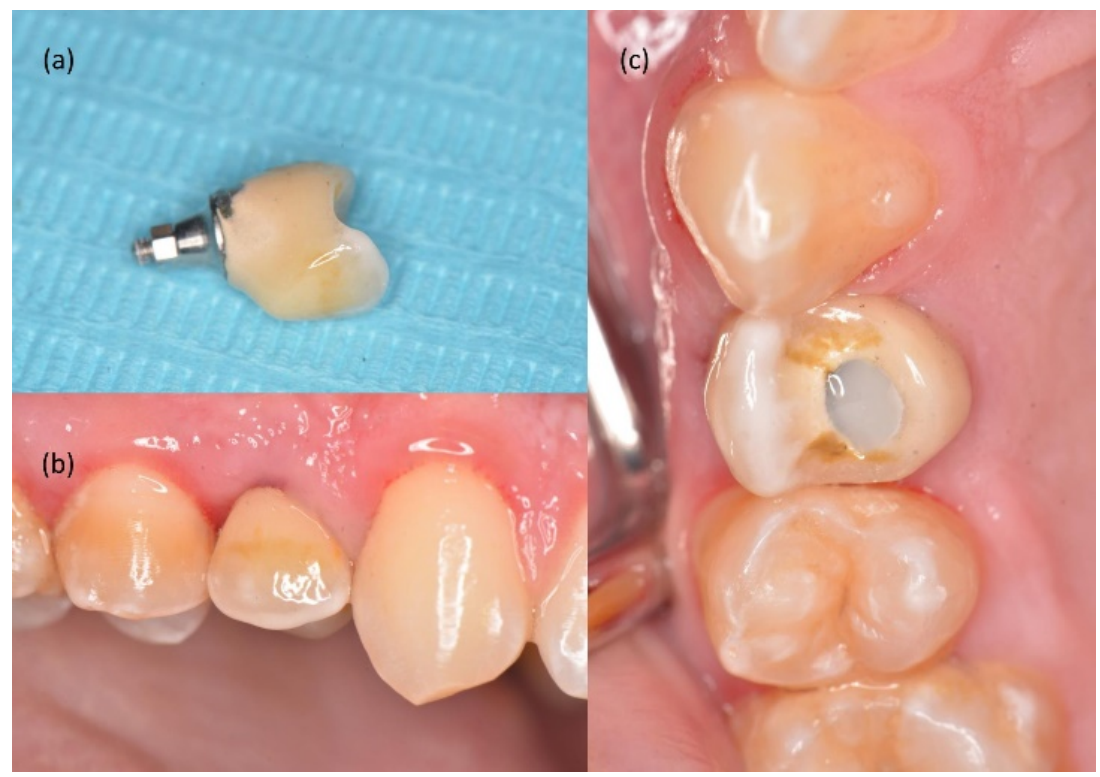

Figure 6. Final crown insertion: a: abutment, and final PFM crown, abutment and crown cemented to turn it into screw retained crown. b: buccal View of the final PFM screw retained restoration. c: occlusal View of the final PFM Screw retained restoration 


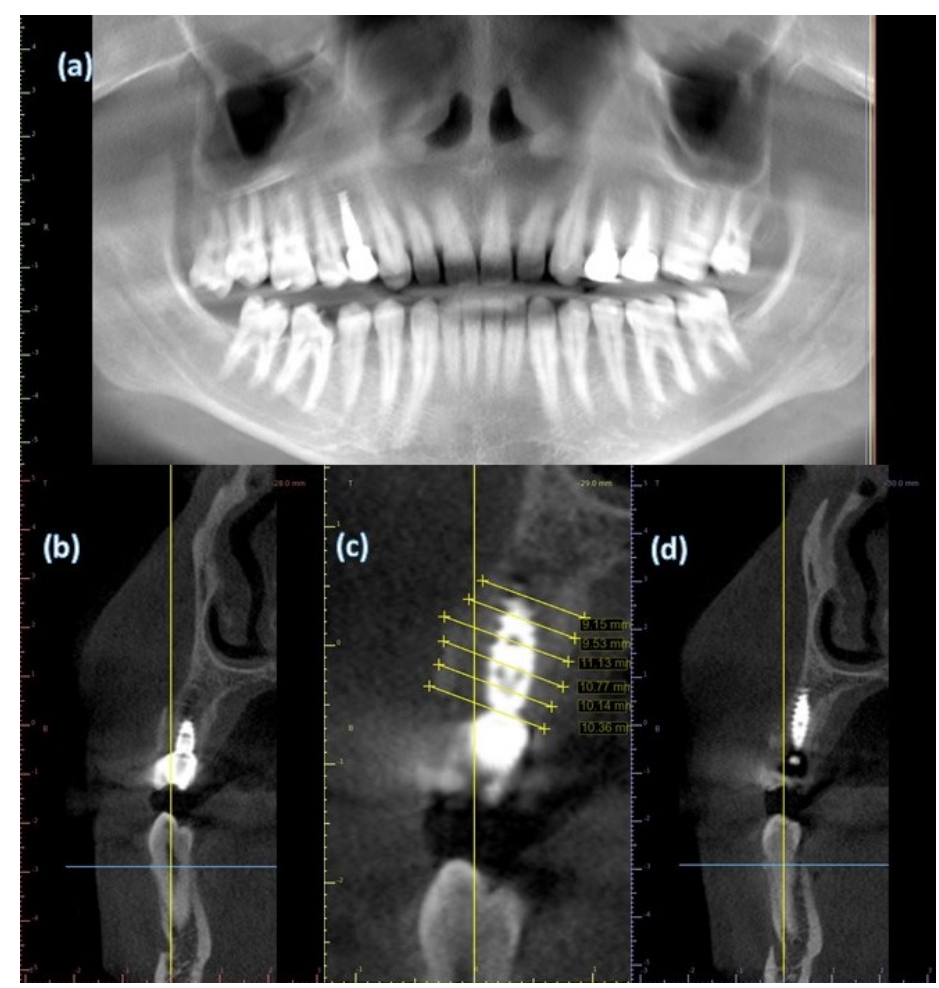

Figure 7. 6-month post-operative CBCT: a: Panoramic view, shows interproximal bone around the implant. b,c,d: Cross-sectional view, relation between the buccal and palatal shield and the implant

Clinical examination showed comparable soft tissue contour with the neighboring teeth (Figure 6: b,c). CBCT was taken directly after final prosthesis delivery showed the bone height interproximal to the implant, the relation between buccal and palatal shields and the implant, and the bulk of the bone around the implant. Measurement of the bucco-palatal width at the bone are demonstrated in (Table 1). (Figure 7:a,b,c,d)

Volumetric alveolar bone changes evaluation:

Pre- and 6-month-post- operative CBCT data sets were imported into Simplant software (Simplat, Materialise Inc, Belgium) were a mask creation tool was used to segment bane, remaining root, implant and its restoration, utilizing threshold corresponding to these structures gray-scale values. The $3 \mathrm{D}$ image of each volume was then generated and exported as STL files.

The STL files for the 3D Volumes of the alveolar bone were imported into the reverse engineering software (Geomagic Studio 2012, USA). The created pre- and postoperative volumes were then registered and superimposed. The area of interest of the alveolar bone was then defined at the mesial and distal interproximal area, extending down to the root apex (Figure 8: a,b).

Quantitative alveolar bone changes were determined by comparing pre- and post- surgical CBCT data sets with digital subtraction of remaining root, Implant and its restoration, respectively, for accurate measurements. This task was accomplished by separating remaining root, implant and its restoration from pre- and post-operative masks respectively (Figure 9: a).

The defined alveolar bone areas were delineated into three zones (coronal, middle, apical) for quantitation (3mm height for each), with the pre-operative alveolar crest serving as a reference point. For each zone, volume was calculated individually in cubic $\mathrm{mm}$ using a volumetric analysis tool (Figure 9: b,c,d).
Representative alveolar ridge volume measurements at baseline and at 6 months for each zone are presented in (Table 2). Results shows 5.07\% volume loss in the coronal zone, and volume gain in the middle and apical zones (2.45,1.44 respectively). Average $3 \mathrm{~d}$ deviation analysis was minimal (-0.052mm, Avg+/-: 0.128/-0.232, SD 0.48).

Volumetric ridge contour changes analysis:

The two pre- and post- surgical study casts were optically 3D laser scanned (KaVo ARCTICA AutoScan, Germany), the generated 3d model data were saved as STL files, and these files were then imported to into reverse engineering software (Geomagic Studio 2012, USA).

The pre- and post- surgical casts were then registered and superimposed. Digital trimming on sectional planes, mesially and distally to study area, was then performed on superimposed study-cast models. To accurately quantify the ridge volume changes at 6-month post-surgery, the remaining root was removed digitally from the presurgical 3D model. The 3D tooth model from preoperative CBCT scan was first superimposed on the pre-operative study cast model, digital removal of the target remaining root was accomplished using a Boolean Subtraction tool to provide an equivalent image to the post-operative model of the jaw (Figure 10: a,b,c,d,e).

Quantitative ridge contour changes were measured in three successive zones (Coronal, Middle, and apical) (3mm height for each) using the highest pre-operative socket contour as a reference point. The volume of each zone of the suctioned socket was calculated individually in cubic mm using volumetric analysis tool (Figure 11: a,b,c,d,e)

Representative ridge volume measurements of each zone at baseline and 6 months later are noted in (Table 3). Results shows $27.05 \%$ volume loss in the coronal zone, and in the middle and apical zones (-6\%, $-3.8 \%$ respectively). Average 3d deviation analysis was minimal (-0.122mm, Avg+/-: 0.029/-0.202, SD 0.263). 

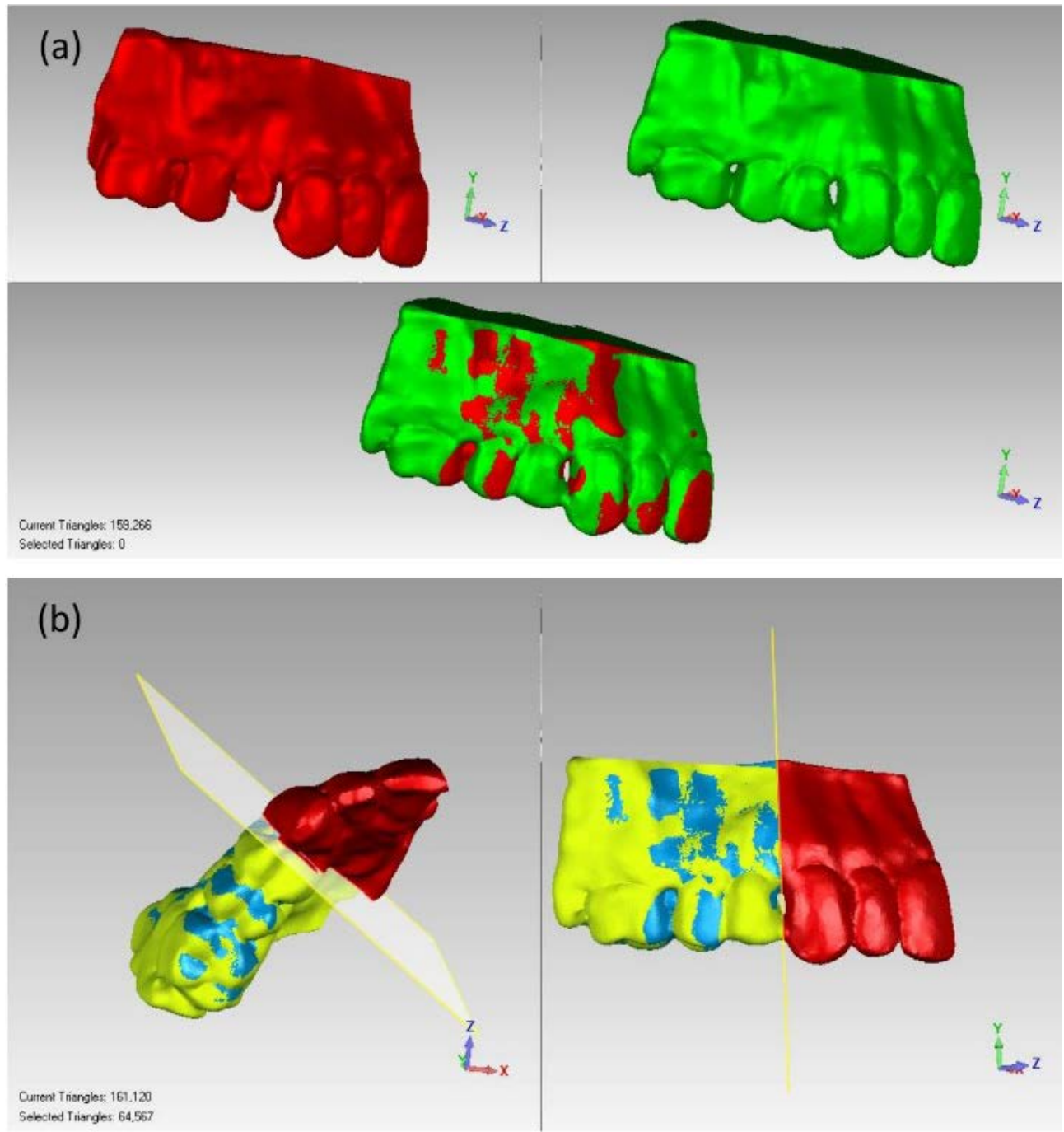

Figure 8. Representative images of 3D rendered CBCT volumes at baseline and 6-month: a: 3D alveolar bone volumes registration and superimposition. b: defining alveolar bone area of interest
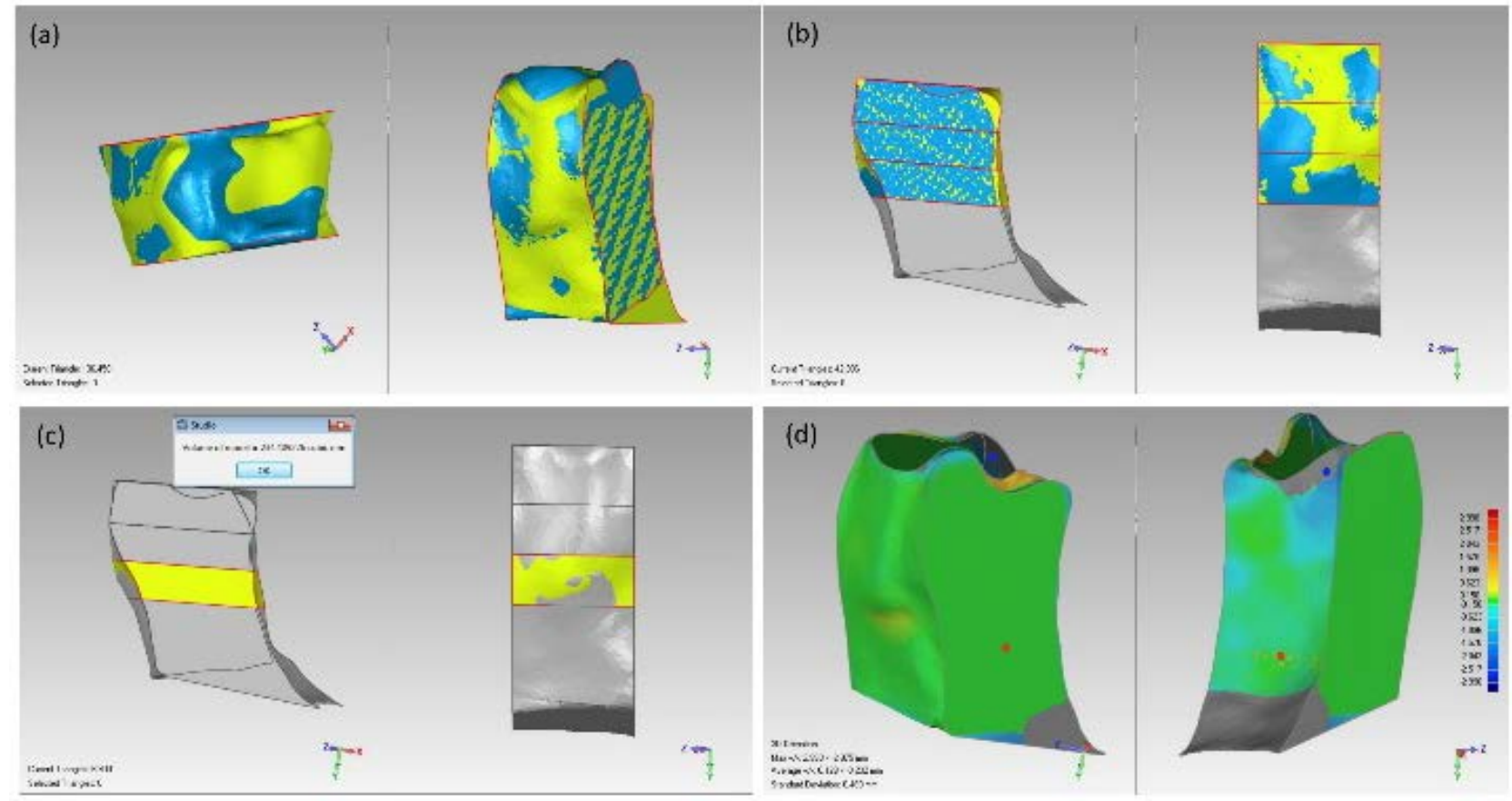

Figure 9. Quantitation of defined alveolar bone area: a: digital subtraction of remaining root, implant and its restoration from the pre- a postintervention alveolar bone area respectively. b,c: three zones defined for quantitation, 1) coronal zone (0-3mm), 2) middle zone (3-6mm), 3) apical zone (6-9mm). d: volumetric 3D deviation analysis 
Table 2. Volumetric deviation analysis of pre- and 6-month-post- operative 3D-rendered volumes of alveolar bone

\begin{tabular}{|c|c|c|c|}
\cline { 2 - 4 } \multicolumn{1}{c|}{} & Pre-surgical & post-surgical & \multicolumn{1}{c|}{} \\
\hline Coronal & 258.31 & 245.21 & $-5.07 \%$ \\
\hline Middle & 238.36 & 244.19 & $+2.45 \%$ \\
\hline Apical & 231.07 & 234.4 & $+1.44 \%$ \\
\hline
\end{tabular}

\begin{tabular}{|c|c|}
\hline \multicolumn{2}{|c|}{ 3D Diviation } \\
\hline max ${ }^{+}$ & +2.99 \\
\hline max- & -2.975 \\
\hline avg & -0.052 \\
\hline avg+ & +0.128 \\
\hline avg- & -0.232 \\
\hline SD & 0.48 \\
\hline
\end{tabular}

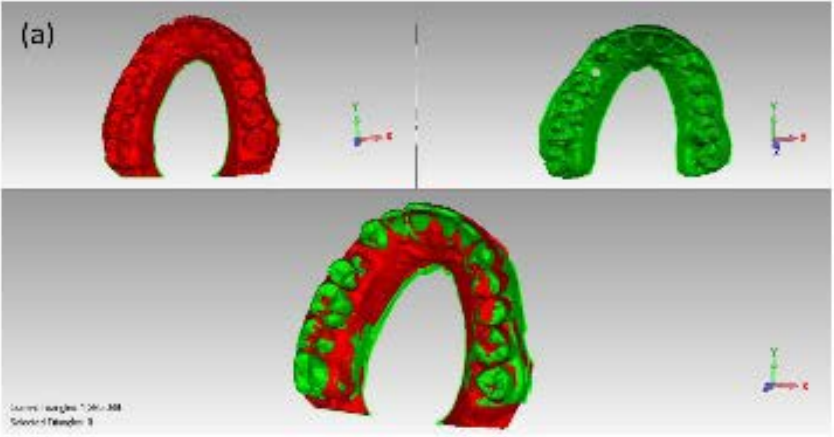

(b)

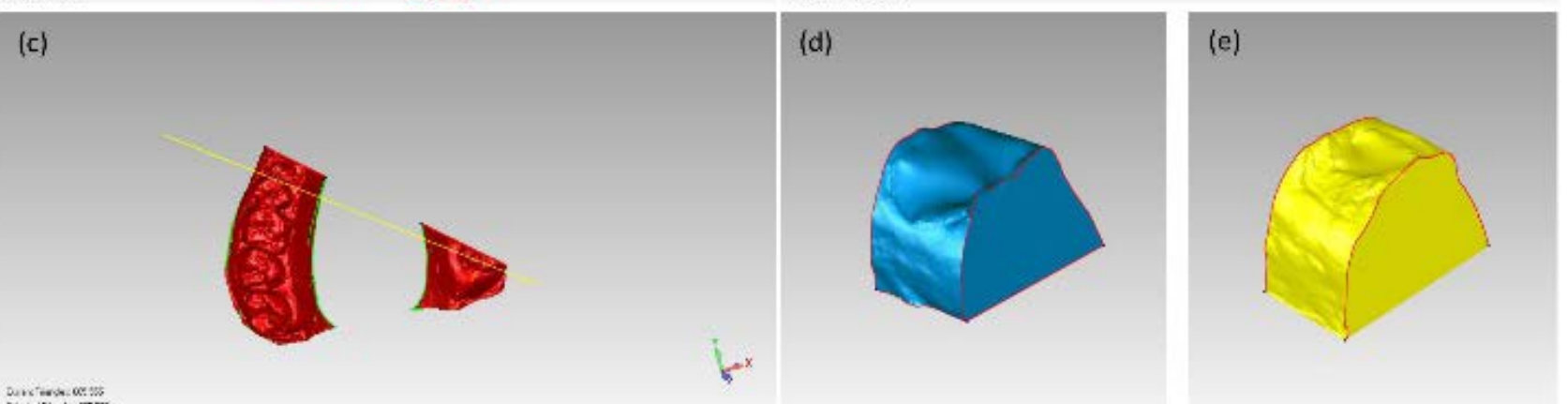

Figure 10. 3D scan of baseline and 6-month study cast models: a: 3D model registration and superimposition. b,c: defining ridge area of interest, d: predefined ridge area following digital subtraction of remaining root. E: 6-month ridge area

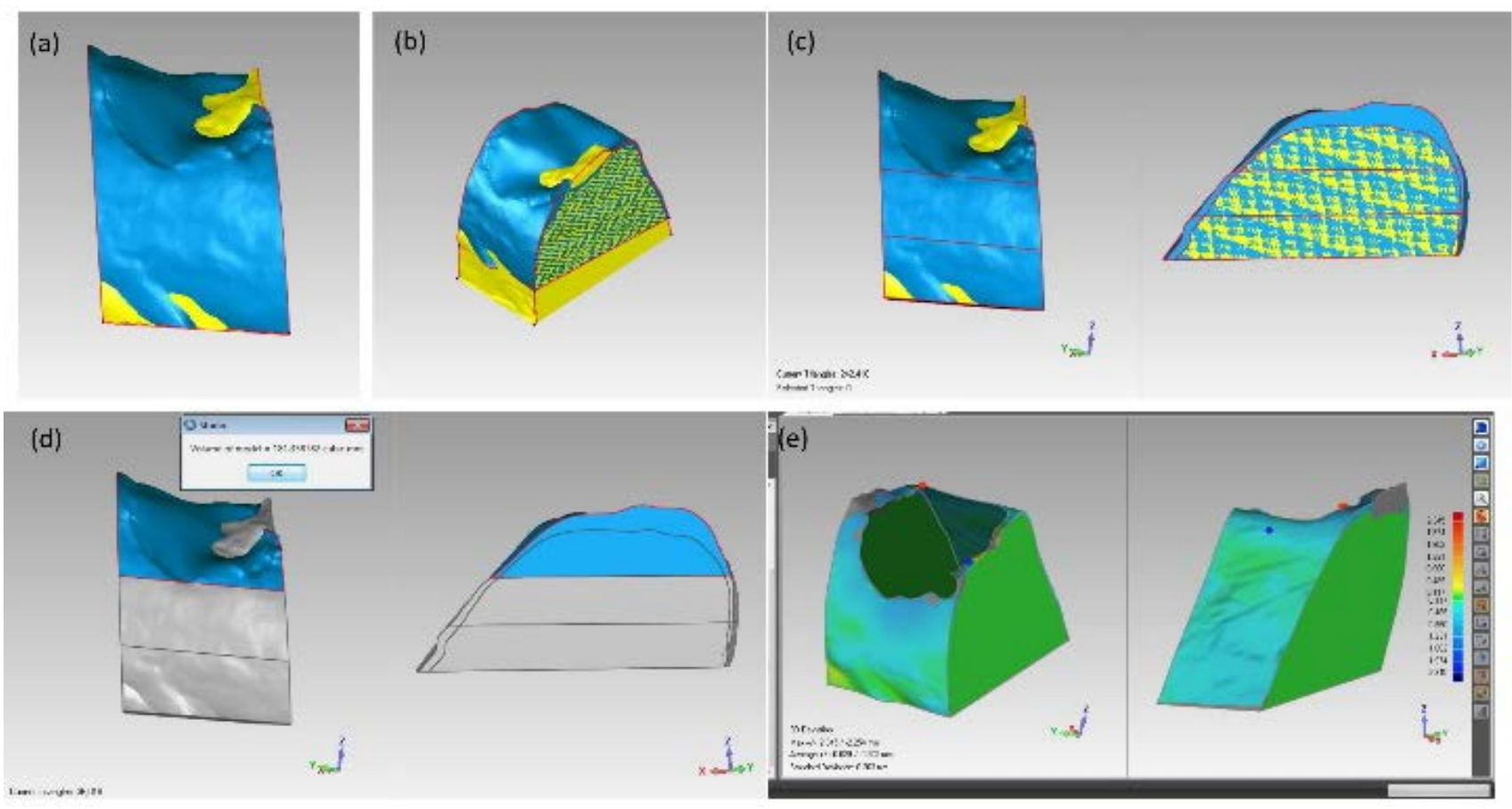

Figure 11. Quantitation of defined ridge area: a,b: superimposed defined area. c,d: three zones defined for quantitation, 1) coronal zone (0-3mm), 2) middle zone (3-6mm), 3) apical zone (6-9mm). e: volumetric 3D deviation analysis 
Table 3. Volumetric deviation analysis of pre- and 6-month-post- operative 3D-rendered ridge volumes

\begin{tabular}{|c|c|c|c|}
\cline { 2 - 4 } \multicolumn{1}{c|}{} & Pre- cast & Post- cast & \\
\hline Coronal & 181.33 & 132.28 & $-27.05 \%$ \\
\hline Middle & 244.4 & 230.56 & $-6 \%$ \\
\hline Apical & 254.07 & 244.4 & $-3.8 \%$ \\
\hline
\end{tabular}

\begin{tabular}{|c|c|}
\hline \multicolumn{2}{|c|}{ 3D Diviation } \\
\hline max ${ }^{+}$ & +2.345 \\
\hline max- & -2.254 \\
\hline avg & -0.122 \\
\hline avg+ & +0.029 \\
\hline avg- & -0.202 \\
\hline SD & 0.263 \\
\hline
\end{tabular}

\section{Discussion}

Immediate implant placement is a well-documented treatment following tooth extraction [12]. However, the outcome of implant treatment is no longer measured exclusively in terms of implant survival, but in terms of esthetic and functional success of the final prosthetic treatment $[13,14]$. These in term depends on optimal placement of the implant, which is influenced by its vertical and horizontal position that depends on alveolar ridge dimension [15]. Ferrus and Coworkers 2009, in their study utilizing a linear measurement, reported a horizontal bone reduction of $(1.1 \pm 1.1 \mathrm{~mm})(32 \%)$ and vertical bone reduction of $(0.7 \pm 1.4 \mathrm{~mm})$ with immediate implant placement in the premolar area [16]. In order to overcome the negative effect of associated tissue remodeling following tooth extraction, various treatment approaches had been described such as graft materials and barrier membranes, However, a complete preservation of the ridge dimension have not yet been documented [5,17,18,19,20].

The socket shield technique had progressed from the early concept started in 1950 that root retention limits tissue alteration following extraction, with the preservation of the root with the periodontal ligament and fibers that will avoid the physiologic remodeling of the extraction socket $[6,7,8,9,10]$. Histologic evidence on socket shield confirmed that retained attachment of the remaining root fragment via a physiologic periodontal ligament is free of any inflammatory response, and that the bone crest shows an absence of active remodeling, moreover, the coronal soft tissue demonstrated a physiologic junctional epithelium free of any inflammatory response [11].

While the literature on Socket shield reported preservation of the buccofacial tissues, it should be noted that absolute preservation has not yet been shown. Baumer and coworkers, 2010, analyzed the volumetric change in the alveolar ridge in a case and showed a mean loss of $0.88 \mathrm{~mm}$ labially with a maximum of $1.67 \mathrm{~mm}$ and a minimum of $0.15 \mathrm{~mm}$ [21]. Later, Chen and coworkers, 2013, reported $0.72 \mathrm{~mm}$ of buccal resorption [22]. Although this technique offered a solution for post extraction ridge alteration in the buccal side only, it did not mention the exact alteration in ridge dimension before and following the procedure.

In this case, CBCT measurement at bone crest level, and every other $2 \mathrm{~mm}$ apically till $10 \mathrm{~mm}$, showed a very minimal alveolar bone bucco-palatal change in cross section views (Table 1), That was below the range of $0.1 \mathrm{~mm}$, with obvious sudden drop in the width at the apical level to almost $1 \mathrm{~mm}$. this apical area had a fenestration where the apex of the buccal root has been resected, although it was filled with the grafting material, it did not prevent ridge dimension loss at this level.

The methodology used in this case report, firstly for alveolar bone volume changes analysis, with superimposition of pre- and 6-month post- intervention CBCT jaw images, followed by digital subtraction of remaining root, implant and its restoration respectively. And secondly for ridge volume changes analysis with superimposition of pre- and post- intervention 3d generated casts models, allowed for calculating of volume changes using a specific computer software (Geomagic Studio 2012, USA). Results of the current case showed a promising preservation of alveolar bone with average loss in volume of $(-0.052 \mathrm{~mm}$, SD 0.48$)$, as well as, a promising preservation of ridge contour with average loss in volume of $(-0.122 \mathrm{~mm}$, SD 0.263$)$.

With the scarcity of the research focusing on optimal esthetic and functional placement of implants in the posterior region of the oral cavity, this case report, with its limitation, may provide an insight of the importance of providing optimal implant treatment on the whole oral cavity. In this case report, the application of buccal and palatal socket shield technique combined with immediate implant placement for replacing a failing multi-rooted tooth in the upper posterior region in the oral cavity obviously maintains the ridge shape. The good function of the prosthesis and the health of the peri implant tissue are observed. Further studies with larger scale of evidence and long-term follow up are needed to substantiate the validity of this technique.

\section{Acknowledgments}

The expert assistance of Dr. Mostafa Omran in three-dimensional volumetric analysis of data sets is acknowledged

\section{Conflict of Interest and Source of Funding}

The authors have stated explicitly that there are no conflicts of interest in connection with this article.

\section{References}

[1] AMLER MH, JOHNSON PL, SALMAN I. Histological and histochemical investigation of human alveolar socket healing in undisturbed extraction wounds. J Am Dent Assoc [Internet]. 1960 Jul 1 [cited 2017 Dec 20]; 61(1): 32-44. 
[2] Scala A, Lang NP, Schweikert MT, de Oliveira JA, Rangel-Garcia I, Botticelli D. Sequential healing of open extraction sockets. An experimental study in monkeys. Clin Oral Implants Res. 2014; 25(3): 288-95.

[3] Schropp L, Wenzel A, Kostopoulos L KT. Bone healing and soft tissue contour changes following single-tooth extraction: A clinical and radiographic 12- month prospective study. Int $J$ Periodontics Restor Dent. 2003; 23(4): 313-23.

[4] Wang RE, Lang NP. Ridge preservation after tooth extraction. Clin Oral Implants Res. 2012;23(SUPPL.6): 147-56.

[5] Araújo MG, Sukekava F, Wennström JL, Lindhe J. Ridge alterations following implant placement in fresh extraction sockets: An experimental study in the dog. J Clin Periodontol. 2005; 32(6): 645-52.

[6] Miller PA. Complete dentures supported by natural teeth. $J$ Prosthet Dent [Internet]. 1958 Nov 1 [cited 2017 Dec 20]; 8(6): 924-8.

[7] Morrow RM, Feldmann EE, Rudd KD, Trovillion HM Tooth-supported complete dentures: An approach to preventive prosthodontics. J Prosthet Dent [Internet]. 1969; 21(5): 513-22.

[8] MALMGREN B, CVEK M, LUNDBERG M, FRYKHOLM A. Surgical treatment of ankylosed and infrapositioned reimplanted incisors in adolescents. Eur J Oral Sci. 1984; 92(5): 391-9.

[9] Salama M, Ishikawa T, Salama H, Funato A, Garber D. Advantages of the root submergence technique for pontic site development in esthetic implant therapy. Int $J$ Periodontics Restorative Dent [Internet]. 2007; 27(6): 521-7.

[10] Filippi A, Pohl Y, Von Arx T. Decoronation of an ankylosed tooth for preservation of alveolar bone prior to implant placement. Dent Traumatol. 2001; 17(2): 93-5.

[11] Hürzeler MB, Zuhr O, Schupbach P, Rebele SF, Emmanouilidis N, Fickl S. The socket-shield technique: A proof-of-principle report. J Clin Periodontol. 2010; 37(9): 855-62.

[12] Lang NP, Pun L, Lau KY, Li KY, Wong MCM. A systematic review on survival and success rates of implants placed immediately into fresh extraction sockets after at least 1 year. Vol. 23, Clinical Oral Implants Research. 2012. p. 39-66.
[13] Buser D, Martin W, Belser UC. Optimizing esthetics for implant restorations in the anterior maxilla: anatomic and surgical considerations. Int J Oral Maxillofac Implants. 2004;19 Suppl: 43-61.

[14] Darby I, Chen ST, Buser D. Ridge preservation techniques for implant therapy. Int J Oral Maxillofac Implants. 2009; 24 Suppl: 260-71.

[15] Iasella JM, Greenwell H, Miller RL, Hill M, Drisko C, Bohra AA, et al. Ridge Preservation with Freeze-Dried Bone Allograft and a Collagen Membrane Compared to Extraction Alone for Implant Site Development: A Clinical and Histologic Study in Humans. $J$ Periodontol [Internet]. 2003; 74(7): 990-9.

[16] Ferrus J, Cecchinato D, Pjetursson EB, Lang NP, Sanz M, Lindhe J. Factors influencing ridge alterations following immediate implant placement into extraction sockets. Clin Oral Implants Res. 2010; 21(1): 22-9.

[17] Araújo M, Linder E, Lindhe J. Effect of a xenograft on early bone formation in extraction sockets: An experimental study in dog. Clin Oral Implants Res. 2009; 20(1): 1-6.

[18] Lekovic V, Camargo PM, Klokkevold PR, Weinlaender M, Kenney EB, Dimitrijevic B, et al. Preservation of Alveolar Bone in Extraction Sockets Using Bioabsorbable Membranes. J Periodontol [Internet]. 1998; 69(9): 1044-9.

[19] Lekovic V, Kenney EB, Weinlaender M, Han T, Klokkevold P, Nedic M, et al. A Bone Regenerative Approach to Alveolar Ridge Maintenance Following Tooth Extraction. Report of 10 Cases. J Periodontol [Internet]. 1997; 68(6): 563-70.

[20] Chen ST, Beagle J, Jensen SS, Chiapasco M, Darby I. Consensus statements and recommended clinical procedures regarding surgical techniques. Int $J$ Oral Maxillofac Implants [Internet]. 2009; 24 Suppl: 272-8.

[21] Bäumer D, Zuhr O, Rebele S, Schneider D, Schupbach P, Hürzeler M. The socket-shield technique: first histological, clinical, and volumetrical observations after separation of the buccal tooth segment - a pilot study. Clin Implant Dent Relat Res. 2015; 17(1): 71-82.

[22] Chen C. Socket Shield Technique for Ridge Preservation: A Case Report. J Prosthodont Implantol [Internet]. 2013; 2(2): 16-21. 